\title{
The Norwegian Society for Pharmacoepidemiology
}

\author{
Angela Lupattelli ${ }^{1}$, Øystein Karlstad ${ }^{2}$, Anders Engeland ${ }^{2,3}$, Lars Småbrekke ${ }^{4}$, Kristine Olsen ${ }^{5}$, \\ Aina Øvrebust ${ }^{6}$ and Marit Waaseth ${ }^{4}$ \\ 1) Pharmacoepidemiology and Drug Safety Research Group, Department of Pharmacy, University of Oslo \\ 2) Department of Chronic Diseases and Ageing, Division of Mental and Physical Health, Norwegian Institute of Public Health \\ 3) Department of Global Public Health and Primary Care, University of Bergen \\ 4) Department of Pharmacy, UiT The Arctic University of Norway \\ 5) Department of Drug Statistics, Norwegian Institute of Public Health \\ 6) Department of Safe Use, Norwegian Medicines Agency \\ Correspondence: angela.lupattelli@farmasi.uio.no
}

This is an open access article distributed under the Creative Commons Attribution Licence, which permits unrestricted use, distribution, and reproduction in any medium, provided the original work is properly cited.

The Norwegian Society for Pharmacoepidemiology (NFFE) is a multidisciplinary, nation-wide network of professionals involved in the field of pharmacoepidemiology. Pharmacoepidemiology is the science that bridges epidemiologic methodology with clinical pharmacology and clinical pharmacy, for studying the use, effectiveness, value and safety of pharmaceuticals ${ }^{1}$.

The foundation of NFFE took into account the growing value of real-world data in assessing potential benefits and risks of medication use, and capitalized on the growing availability of linkable, nation-wide health registries and large population-based cohorts in Norway. In this short commentary, we briefly describe the history and mission of the society, and our current and future activities to foster high-quality research and education at national and international level.

\section{HISTORY AND MISSION}

NFFE was founded in March 1998 with the initial name "Forum for pharmacoepidemiology". The initiative came from experienced pharmacoepidemiologists who saw the need for a national forum for researchers within the field of pharmacoepidemiology and drug utilization research $^{2}$. The objective was to create a crossprofessional national network of people with an interest in issues related to medication use, and to facilitate discussions, idea exchange and professional collaboration. Since its origin, the society has represented the Norwegian subgroup of the European Drug Utilization Research Group (EURODURG), an independent group of professionals from different fields sharing a common interest in drug utilization and pharmacoepidemiology $y^{3}$. The pioneer board included Anne Elise Eggen (leader), Jørund Straand, Kari Furu, Tarjei Rygnestad, Karen Ulshagen, Ivar Aursnes, and Marit Rønning.

NFFE shares common goals and interests with the Norwegian Epidemiological Association (NOFE) ${ }^{3}$, founded in 1990. These common goals include, among others, the advocacy for the importance of epidemiological research in generating necessary knowledge to promote population health. It is the specific focus on medications that makes NFFE a distinct, yet comple- mentary society to NOFE. Indeed, many of our members are also members of NOFE and participate actively at the NOFE annual conference.

The mission of NFFE is to contribute to optimizing appropriate use of medications in the Norwegian population and to advance population health, by providing a national forum for exchange of research findings and educational opportunities. The society advocates the value of pharmacoepidemiological real-world data in supporting regulatory and clinical decision-making. It promotes high-quality, methodologically sound research and educational activities across different research and clinical environments in the country ${ }^{4}$. This mission aligns with those of the pharmacoepidemiology societies in other Nordic countries, such as in Denmark (Dansk Selskab for Farmakoepidemiologi, DSFE) or Sweden (Svensk läkemedelsepidemiologisk förening, SLEF).

The society encourages active communication and collaboration between researchers, healthcare professionals, regulatory scientists, and policy makers. The interdisciplinary composition of the membership is an important strength of our society. The background of our members represent the various scientific disciplines involved in studying medications, that is: (i) researchers within the academia, public health institutions and hospitals; (ii) healthcare professionals, including doctors, pharmacists, nurses, and midwives; (iii) scientists within the four medicines information and pharmacovigilance centers (RELIS) in Norway, the Norwegian Medicines Agency, or the pharmaceutical industry; and (iv) students within pharmacy, public health or medicine. The society welcomes as members everyone interested in the field of pharmacoepidemiology, clinical pharmacology, clinical pharmacy, epidemiology, pharmacoeconomics, and/or drug utilization.

The incorporation of pharmacoepidemiological research and its applications in educational programs at bachelor, master and $\mathrm{PhD}$ level, is an important goal of NFFE. The society encourages professional and educational development of future scientists via sponsoring workshops and guest lectures, participation at the annual meetings of the society, and by offering research stipends for students at the master level. 


\section{CURRENT AND FUTURE ACTIVITIES}

Until recently, NFFE has organized an annual meeting focusing on selected topics, including invited keynote speakers and sessions with oral presentations. To foster national networking, methodological discussion, and education, our society will collaborate with NOFE and contribute to its annual conference in 2021 and years ahead, by dedicating one or more parallel sections to pharmacoepidemiology. This strategy will strengthen collaboration and networking between the members of the two societies.

Our society seeks to facilitate interaction and collaboration between Norwegian and international researchers in pharmacoepidemiology. Through promoting active participation in Nordic and International networks and meetings, we contribute to disseminate Norwegian pharmacoepidemiological research and initiate collaboration across borders. The Nordic PharmacoEpidemiological Network (NorPEN) is a network of researchers with the purpose of facilitating research within the field of pharmacoepidemiology in the Nordic countries. Within this collaboration, multiple, successful research findings have been generated $^{5,6}$. Multiple educational opportunities for postgraduate and $\mathrm{PhD}$ level students have been and are currently available. NFFE also participates and contributes annually to the International Society for Pharmacoepidemiology (ISPE).

Our goals for the future include a broadening of the educational and training portfolio for our members, including students, in close collaboration with the pharmacoepidemiology societies in the Nordic countries and with NorPEN. For instance, digital platforms provide opportunities for more flexible research disseminations and methodological discussions, both in time and space. Further, we aim to expand and strengthen the scientific disciplines which are less represented in our society. For instance, we encourage more active involvement of scientists and medication experts employed by the pharmaceutical industry, drug information centers, hospital and primary care settings, as well as government agencies.

We welcome all professionals with an interest in observational drug research, whether their background is in epidemiology, pharmacoeconomics, biostatistics, medicine, nursing, pharmacology, or pharmacy. Join NFFE and contribute to our mission of optimizing appropriate use of medications in the Norwegian population and to advance public health. See Box 1 for link to the NFFE webpage and information on how to join.

\section{Box 1. The Norwegian Society for Pharmacoepidemiology (NFFE)}

About the society: https://farmakoepinorge.wordpress.com/

NFFE on Facebook:

https://www.facebook.com/groups/392201924249013

How to sign up? Use the entry form on the web-page, or contact any of the authors of this paper.

\section{REFERENCES}

1. Strom BL. What is pharmacoepidemiology? In: Strom BL, Kimmel SE, Hennessy S (Eds.): Pharmacoepidemiology. Wiley-Blackwell, 2011: 3-21.

2. Eggen AE, Straand J (Eds.). Pharmacoepidemiology - a bridge science. Norsk Epidemiologi 2001; 11 (1).

3. International Society for Pharmacoepidemiology. EURODURG. National Groups and Contact Persons. https://www.pharmacoepi.org/eurodurg/national-groups-and-contact-persons/. Accessed May 9, 2021.

4. Norsk forening for farmakoepidemiologi. Statutter. https://farmakoepinorge.wordpress.com/statutter/. Accessed May 9, 2021.

5. Furu K, Wettermark B, Andersen M, Martikainen JE, Almarsdottir AB, Sørensen HT. The Nordic countries as a cohort for pharmacoepidemiological research. Basic Clin Pharmacol Toxicol 2010; 106 (2): 86-94.

6. NorPEN. Nordic PharmacoEpidemiological Network. Publications. http://www.norpen.org/pages/publications.html. Accessed May 10, 2021. 